\title{
Utility of Synchronous Spectrofluorimetric Method for Rapid Selective Determination of Bimatoprost: Stress Stability Study and Green Analytical Application
}

Mohammed W' ${ }^{1}$, Safaa $\mathrm{T}^{2}$, Abou El-Alamin MM $^{2}$, Nahla NS $^{3}$ and Elabd MA M $^{3 *}$

${ }^{1}$ Department Analytical Chemistry, Faculty of Pharmacy, Mansoura University, Egypt

${ }^{2}$ Department Analytical Chemistry, Faculty of Pharmacy, Helwan University, Egypt

${ }^{3}$ Department of Pharmaceutical Chemistry, National Organization for Drug Control and Research, 9 Abou-Hazem street, Giza, Egypt

\begin{abstract}
Stability indicating Synchronous spectrofluorimetric (SF) method has been proposed and validated for the determination of bimatoprost in presence of its acid, base, and oxidative degradation products by measuring SF at $272 \mathrm{~nm}$ using delta lamba $(\Delta \lambda)=30 \mathrm{~nm}$ in water. Bimatoprost was subjected to stress conditions of $2 \mathrm{M} \mathrm{HCL}, 2 \mathrm{M}$ $\mathrm{NaOH}$ and $30 \% \mathrm{H}_{2} \mathrm{O}_{2}$. The identification of degradation products were done by LC-MS. The pathway of degradation was postulated. The effect of different experimental parameters on the fluorescence of the drug was studied and optimized. The range of linearity was over $25-250 \mathrm{ng} / \mathrm{mL}$, the detection limit of $0.005 \mathrm{ng} / \mathrm{mL}$, and quantitation limit of $0.018 \mathrm{ng} / \mathrm{mL}$ for bimatoprost. The developed method was validated according to $\mathrm{ICH}$ guidelines. The accuracy was checked by applying the proposed method for the determination of the drug and it's degradant. The mean recoveries percentages were found to be $99.39 \pm 1.08$. RSD values for precision (repeatability and intermediate) testing was 0.569 and 1.28 respectively. The developed method was applied effectively for analysis of the drug in its ophthalmic formulation. The developed method was statistically compared with the reported method revealing high accuracy with good precision. The suggested method was found to be a green analytical chemistry method; the solvent used is water and hence that method can be suitable for routine analysis of the studied drug without effecting the environment harmfully.
\end{abstract}

Keywords: Bimatoprost; Synchronous spectrofluorimetry; Stress stability study; Validation, Green analytical chemistry; Ophthalmic solution

\section{Introduction}

Bimatoprost, (7-[3,5-dihydroxy-2-(3-hydroxy-5-phenyl-pent-1enyl)- cyclopentyl]-N-ethyl-hept-5-enamide), is antiglaucoma agent (ophthalmic); antihypertensive [1].<smiles>CCNC(=O)CCC/C=C\C[C@H]1[C@H](O)C[C@@H](O)[C@@H]1/C=C/[C@H](O)CCc1ccccc1</smiles>

\section{Bimatoprost}

Bimatoprost is a prostaglandin analog/prodrug used topically (as eye drops) to control the progression of glaucoma and in the management of ocular hypertension. It reduces intraocular pressure (IOP) by increasing the outflow of aqueous fluid from the eyes. It has also been used and prescribed off-label to lengthen eyelashes [2-8].

A literature survey revealed few methods for determination of bimatoprost. Ultra Performance Liquid Chromatography (UPLC) with MS was reported for determination of the drug in presence its impurity (methyl ester) [9] Another two HPLC methods were reported for determination of bimatoprost in bulk and ophthalmic solution [10], and HPLC-Tandem Mass Spectrometry Measurement of Bimatoprost, Latanoprost and Travoprost in Eyelash Enhancing Cosmetic Serums [11].

Also literature reveals there is no spectrofluorometric method was reported for bimatoprost and all of them not provide simple, sensitive, economic method nor eco-friendly, green analytical method.
Spectrofluorimetric method proved to be more selective than normal UV-spectroscopy due to quantitation of substance at characteristic excitation and emission wavelengths [12]. Synchronous spectrofluorimetry provides a greater selectivity and spectral discrimination than common spectrofluorimetry $[9,10]$. Synchronous fluorescence spectroscopy (SFS) has many advantages over conventional fluorescence spectroscopy, including high selectivity, simple spectra, and very low interference [12]. Because of it has sharp, narrow spectrum, so can use in quantification and qualification of many drugs [13].

\section{Aim of work}

It is a powerful technique for resolution of one analyte whose peak is overlapped or hidden by another analyte's large overlapping peak in multi-component analysis. The aim of the presented work was to propose a simple, sensitive, rapid, and economic, eco-friendly, green analytical method for the quantification of bimatoprost in presence of its degradant in drug substance and in ophthalmic dosage form by synchronous spectrofluorimetry based on its native fluorescence. The suggested method was developed so that it is neither use nor produce

*Corresponding author: MahaAbd El-Hamid Elabd, Department of Pharmaceutica Chemistry, National Organization for Drug Control and Research, 9 Abou-Hazem street, Giza, Egypt, Tel: 01001905997; E-mail: mahaelabd@hotmail.com

Received November 12, 2018; Accepted November 22, 2018; Published November 29, 2018

Citation: Mohammed W, Safaa T, Abou El-Alamin MM, Nahla NS, Elabd MA (2018) Utility of Synchronous Spectrofluorimetric Method for Rapid Selective Determination of Bimatoprost: Stress Stability Study and Green Analytical Application. Pharm Anal Acta 9: 600. doi: 10.4172/2153-2435.1000600

Copyright: (c) 2018 Mohammed W, et al. This is an open-access article distributed under the terms of the Creative Commons Attribution License, which permits unrestricted use, distribution, and reproduction in any medium, provided the original author and source are credited. 
Citation: Mohammed W, Safaa T, Abou El-Alamin MM, Nahla NS, Elabd MA (2018) Utility of Synchronous Spectrofluorimetric Method for Rapid Selective Determination of Bimatoprost: Stress Stability Study and Green Analytical Application. Pharm Anal Acta 9: 600. doi: 10.4172/21532435.1000600

Page 2 of 6

harmful chemicals; also it produces minimum waste so it is valid for routine analysis and QC laboratories without bad effect on the environment.

\section{Experimental}

\section{Instrumental}

The emission of all samples was recorded by Cary Eclipse fluorescence spectrophotometric (USA), which connected to IBMPC computer and HP laser jet 1100 series printer. The measurements were against a solvent blank in quartz cuvettes $(1 \mathrm{~cm})$ and scanning at that parameters, Scan speed $=1200 \mathrm{~nm} / \mathrm{min}$, Band width $=1.5 \mathrm{~nm}$, Smoothing=high , and Data Interval=normal $(1 \mathrm{~nm})$.

For adjusting the $\mathrm{pH}$, using Jenway (model 8417) Digital pH meter.

Shimadzu spectrophotometer Model RF-1601, UV/VIS was used.

\section{Chemicals and reagents}

All the chemicals and reagents which used were of analytical grade.

Bimatoprost was supplied by Chemipharm Co, Egypt. The purity was to be $99.80 \%$ according to the certification of manufacturer method [14]. Bimatoprost ophthalmic solution was labeled to contain 0.03\%, El- Sofikopharm Co., Egypt; Batch No. 85543, it was purchased from the market. Methanol, acetonitrile, and Sodium dihydrogen orthophosphate were purchased from Sigma Aldrich (Germany). Hydrochloric acid from Fischer Scientific (UK), and 33\% ammonia, hydrogen peroxide, and sodium hydroxide were from Adwic Co., Egypt. Britton-Robinson Buffer was prepare by mixing $5 \mathrm{~mL}$ of $(8$ $\mathrm{mL} 0.5 \mathrm{M}$ phosphoric acid, $8 \mathrm{~mL} 0.5 \mathrm{M}$ boric acid, $8 \mathrm{~mL} 0.5 \mathrm{M}$ acetic acid) $76 \mathrm{~mL}$ water. Water was prepared by double glass distillation and filtration through a $0.47 \mu \mathrm{m}$ membrane filter (Alltech Associates, USA).

\section{Standard solutions}

Bimatoprost Stock standard solutions $(0.1 \mathrm{mg} / \mathrm{mL})$ : Accurately weighed amount of $10 \mathrm{mg}$ bimatoprost and transferred into volumetric flasks $(100 \mathrm{~mL})$ and dissolved in $5 \mathrm{~mL}$ distillated water. The flask was shaken and with distillated water, that volume was completed.

Hydrogen peroxide-induced degradation: Bimatoprost (5 mg, accurately weighed) was placed in a round-bottomed flasks containing $5 \mathrm{~mL} 30 \% \mathrm{H}_{2} \mathrm{O}_{2}$ and left for $2 \mathrm{~h}$ at room temperature. Then that solution was evaporated at $60^{\circ} \mathrm{C}$ on water bath.

Acid degradation: Bimatoprost (5 mg, accurately weighed) was placed in a round-bottomed flasks containing $5 \mathrm{~mL} 2 \mathrm{M} \mathrm{HCL}$ and left for 2 hour in water bath at $90^{\circ} \mathrm{C}$. Then the solution was neutralized with $2 \mathrm{M} \mathrm{NaOH}$ then evaporated.

Base degradation: Bimatoprost (5 mg, accurately weighed) was placed in a round-bottomed flasks containing $5 \mathrm{~mL} 2 \mathrm{M} \mathrm{NaOH}$ and left for $2 \mathrm{~h}$ in water bath at $90^{\circ} \mathrm{C}$. Then the solution was neutralized with 2 M HCL then evaporated.

Bimatoprost and degradants working standard solutions: From the stock solutions of bimatoprost \& its degradants, $10 \mathrm{~mL}$ and 1 $\mathrm{mL}$ were transferred to volumetric flasks $(100 \mathrm{~mL})$ respectively. The volume was completed to be $100 \mathrm{~mL}$ with HPLC Water to obtain a final concentration of $10 \mu \mathrm{g} / \mathrm{mL}$ of each.

Identification of degradations: The degradation product was identified via LC-MS and scheme of degradation was postulated.

\section{Recommended procedures}

Construction of calibration curve: From working standard solution, aliquots equivalent to $0.025-0.25 \mathrm{~mL}$ of bimatoprost was transferred in sets of volumetric flasks $(10 \mathrm{~mL})$. Then complete the volumes with water to get a set of concentrations $(25-250 \mathrm{ng} / \mathrm{mL})$. Then scan the solutions and record their Synchronous fluorescence spectra at a fixed wavelength difference of $\Delta \lambda=30 \mathrm{~nm}$ and scan rate of $800 \mathrm{~nm} \mathrm{~min}{ }^{-1}$. The SFS was measured at $272 \mathrm{~nm}$ and plotted against corresponding concentrations.

Laboratory prepared mixtures: The developed method was assessed its stability nature by a synthetic mixtures containing different ratios of bimatoprost and its degradations products, then that mixture were analyzed by the developed SFS. Equivalent volumes of bimatoprost and its degradations stock solutions in ratio of $5 \%-20 \%$ were add into a series of $10 \mathrm{~mL}$ volumetric flasks. Then the recommended procedure described under calibration curve was followed.

Pharmaceutical dosage form: An accurately measured volume of ophthalmic solution equivalent to $3 \mu \mathrm{g}$ bimatoprost was added to volumetric flask of $10 \mathrm{~mL}$ capacity, and then complete the volume with distilled water. Then transfer $5 \mathrm{~mL}$ of dosage stock solution to $10 \mathrm{~mL}$ volumetric flask and complete the volume with water to obtain solution with bimatoprost equivalent to $150 \mathrm{ng}$.

\section{Results and Discussion}

Here we concerned with developing a simple, selective and sensitive method for the determination of bimatoprost in pure form and ophthalmic preparation in presence of its degradation products.

Aqueous solution of bimatoprost exhibited a well native fluorescence with excitation at $217 \mathrm{~nm}$ and emission at $285 \mathrm{~nm}$ as shown in Figure 1.

\section{Optimization of fluorescence depended conditions}

The conditions affecting the performance of the developed method were studied and optimized carefully. Each factor was changed individually while others were kept constant. These factors included; $\Delta \lambda$ selection, $\mathrm{pH}$, type of the diluting solvent.

The optimum $\Delta \lambda$ : The synchronous fluorescence scanning technique depended on optimization of $\Delta \lambda$, with regards to its resolution, sensitivity and features. It can directly influence synchronous spectral shape, band width and signal value.

A wide range of $\Delta \lambda(10,30,50,70$ and $100 \mathrm{~nm})$ was examined. When $\Delta \lambda$ was less than $30 \mathrm{~nm}$, the spectra shapes were irregular with weak fluorescence intensities and noisy. On the other hand, when $\Delta \lambda$ was greater than $30 \mathrm{~nm}$, overlapping the peaks of bimatoprost and its

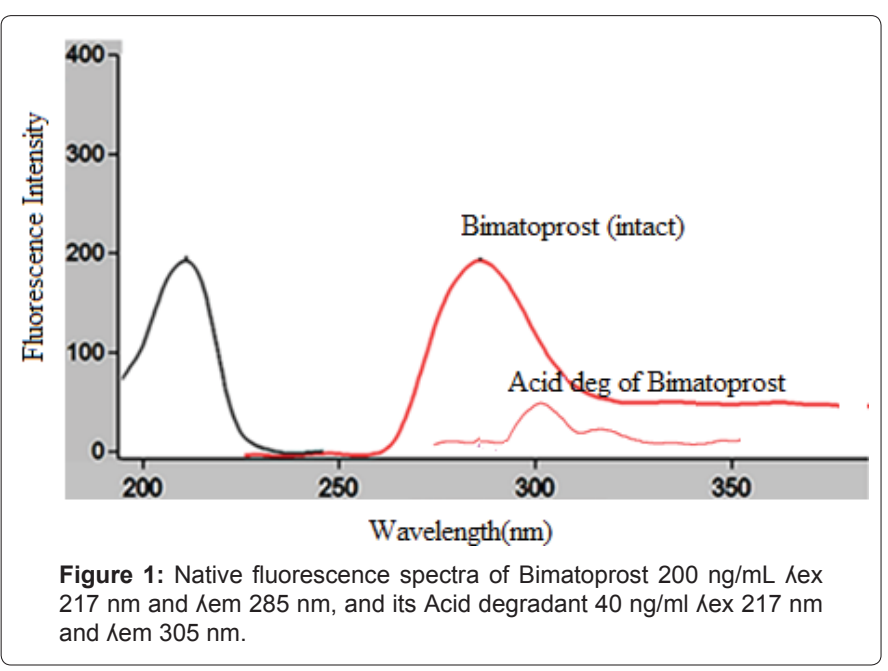


Citation: Mohammed W, Safaa T, Abou El-Alamin MM, Nahla NS, Elabd MA (2018) Utility of Synchronous Spectrofluorimetric Method for Rapid Selective Determination of Bimatoprost: Stress Stability Study and Green Analytical Application. Pharm Anal Acta 9: 600. doi: 10.4172/21532435.1000600

Page 3 of 6

acid degradent was achieved. Therefore, $\Delta \lambda$ of 30 was chosen as optimal for well separation of bimatoprost and its acid degradant mixtures, since it resulted in two well separated peaks with good regular shapes as shown in Figure 2. The prescan of oxidative degradant hasn't fluorescence (Figure 2). The alkali treatment of bimatoprost don't effect on it \& hasn't alkali degradant the drug remain as it is.

Effect of diluting solvent: The proposed procedure was applied using different diluting solvents as, methanol, $0.1 \mathrm{M} \mathrm{HCl}$, acetone, 0.1 $\mathrm{M} \mathrm{NaOH}$, acetonitrile and distilled water. The relative fluorescence intensity for each solution was measured each against the appropriate blank.

The results revealed that disappearance of fluorescence with acetone. Each of diluted aqueous acid, diluted aqueous alkali, acetonitrile and methanol decrease the intensity of fluorescence compared to water. So, water was selected as diluting solvent as it gave the highest synchronous fluorescence intensities compared with the other solvents as shown in
Figure 3. The usage of water is eco-friendly to surrounded environment, where no hazards, and no harmful residues, so that developed method considers green analytical method.

Selection of optimum $\mathrm{pH}$ : The influence of $\mathrm{pH}$ on the synchronous fluorescence intensities of the bimatoprost was studied using BrittonRobinson buffer covering the whole $\mathrm{pH}$ range [1.8-11.58]. The relative fluorescence intensity for each solution was each against the appropriate blank

The synchronous fluorescence intensity of bimatoprost is increased gradually upon increasing the $\mathrm{pH}$ values up to 7.24 and remained constant until $\mathrm{pH}$ 7.9, further increase in $\mathrm{pH}$ resulted in a gradual decrease in the synchronous fluorescence intensities, after which it extremely decreased at $\mathrm{pH} 11.58$ (Figure 3). Therefore the proper $\mathrm{pH}$ of the study was 7 as the water.

Effect of surfactants: The effect of addition of Tween 20, Tween 80 , Cetrimid (1 gram), and Cetrimid ( 2 gram) on the intensity of
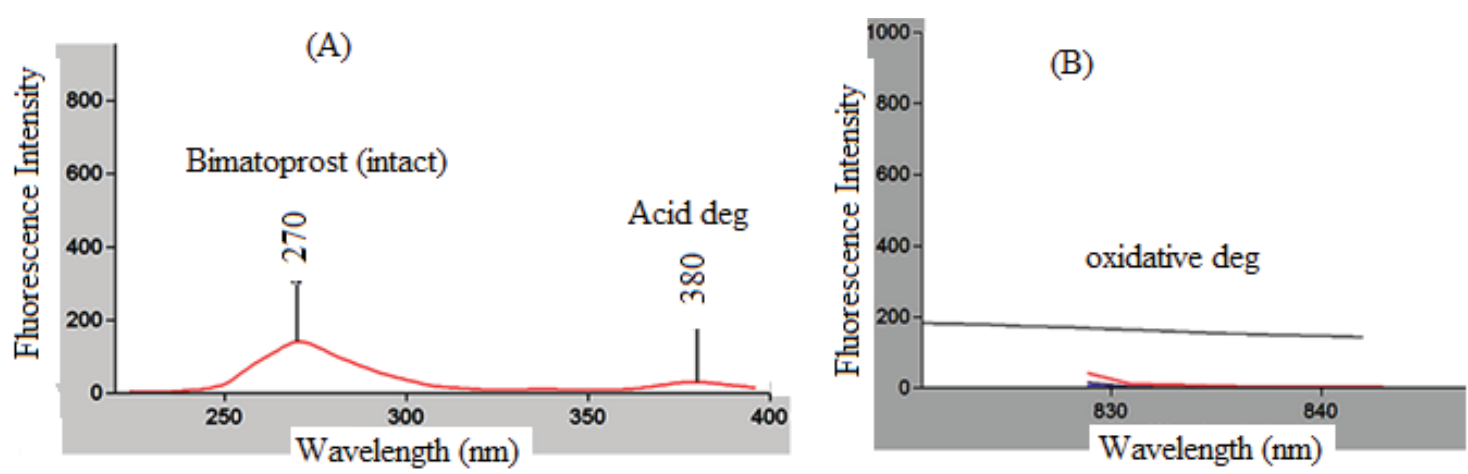

Figure 2: (A) The Spectra of: Bimatoprost $200 \mathrm{ng}$, and acid degradation $40 \mathrm{ng}$ using $\Delta \lambda=30$ in water at $\Lambda 270 \mathrm{~nm}$ for bimatoprost and $\Lambda 380 \mathrm{~nm}$ for acid degradants) (B) prescan of oxidative degradant where has not fluorescence.

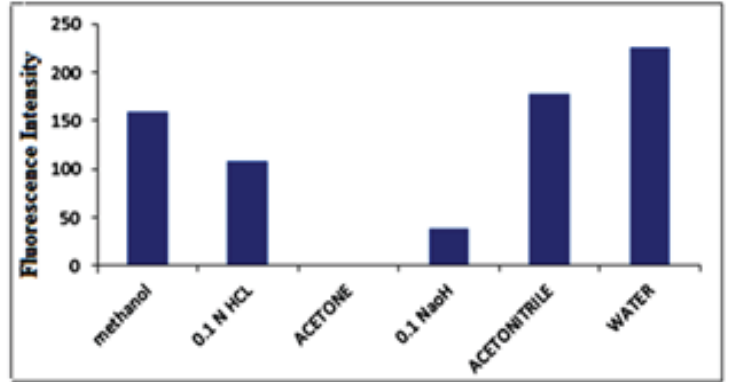

Effect of different solvents

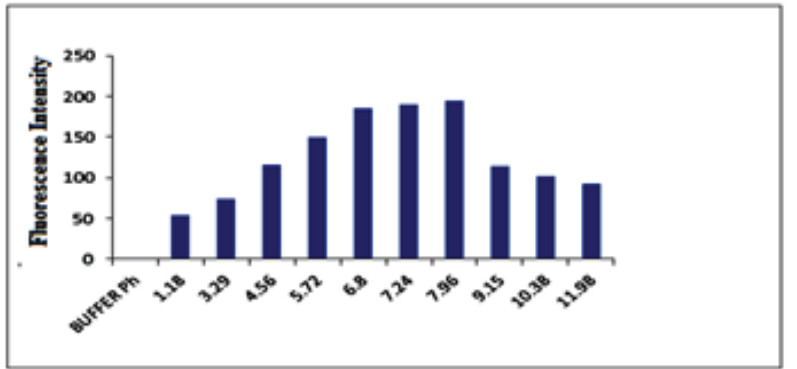

Effect of different Buffer pH

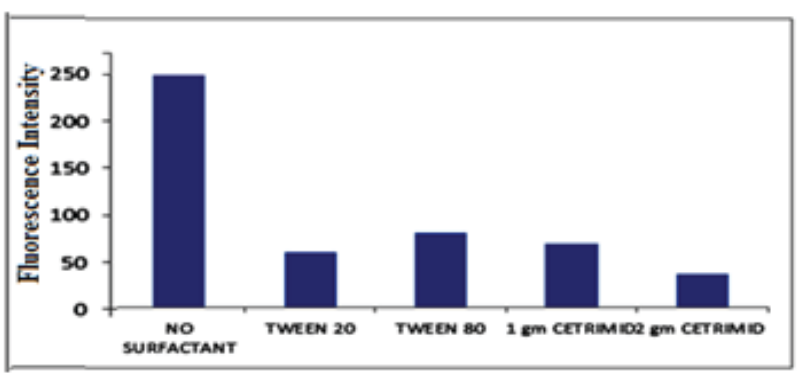

Effect of different types different surfactants

Figure 3: Optimization parameters of SFS of $200 \mathrm{ng} / \mathrm{mL}$ Bimatoprost at $\Lambda \mathrm{em} 270 \mathrm{~nm}$. 
Citation: Mohammed W, Safaa T, Abou El-Alamin MM, Nahla NS, Elabd MA (2018) Utility of Synchronous Spectrofluorimetric Method for Rapid Selective Determination of Bimatoprost: Stress Stability Study and Green Analytical Application. Pharm Anal Acta 9: 600. doi: 10.4172/21532435.1000600

Page 4 of 6

fluorescence of bimatoprost were studied. They haven't effect the intensity of fluorescence of bimatoprost compared to the intensity of it alone in water (Figure 3).

\section{Procedure for the laboratory prepared mixture}

To assess the stability nature of the proposed methods, synthetic mixture containing different ratios of bimatoprost and its degradations were analyzed by the proposed spectrofluorometric and spectrophotometric methods.

Aliquot volumes of bimatoprost and its degradations stock solutions in ratio of $5 \%-20 \%$ were transferred into a series of $10 \mathrm{~mL}$ volumetric flasks was added and diluted to the volume with distilled water, and mixed well. The recommended procedure described under calibration curve was then performed.

\section{Identification of degradants}

Mass spectroscopy was used for structural elucidation of hydrolytic and oxidative degradants of bimatoprost and suggestion of the degradation pathways.

The suggested pathways of hydrolytic and oxidative degradations processes are shown in (Scheme 1).

\section{Method validation}

According to $\mathrm{ICH}$ Q2B recommendations, the validity of the developed method was tested regarding; linearity and range, accuracy, precision and specificity $[15,16]$.

Linearity and range: Upon applying the optimum experimental conditions, the calibration graph was constructed by plotting SFI against the concentration of Bimatoprost $(25-250 \mathrm{ng} / \mathrm{mL})$. The method of least square was applied to yield the regression equation.

Linear correlation coefficients were obtained as shown in Figure 4.
The regression equations found to be:

$\mathrm{Y}=0.9562 \mathrm{X}+52.329 \mathrm{R}^{2}=0.9997$

Where, $\mathrm{Y}=$ synchronous fluorescence, $\mathrm{X}=$ Concentration in $\mathrm{ng} / \mathrm{mL}$ and $\mathrm{r}=$ Correlation coefficient.

The mean percentage recoveries and validations parameters are presented in Table 1.

Accuracy: The accuracy of the proposed methods was proved, the results of the assay of the drug substance was assessed by the developed spectrofluorimetric method and compared with those obtained using manufacture HPLC methods [14].

Statistical comparison of the results obtained by the proposed method and those obtained by the manufacture method using mean recoveries, Student's t-test and variance ratio F-test revealed no significant difference between the two methods regarding accuracy and precision as shown in Table 2, indicating high accuracy and precision of the proposed methods $[15,16]$.

Precision (repeatability and intermediate precision): The intraand inter-day precision were assessed by assaying freshly prepared solutions in triplicate on the same day and on three different days, respectively using the proposed methods. The low RSD of the repeatability (intra-day) and intermediate precision (inter-day) of the results obtained by means of the proposed methods indicate a high precision of these methods and proved to be suitable for quality control of bimatoprost as shown in Table 3 .

Specificity: The specificity of the developed method was emphasized when laboratory prepared mixtures were analyzed. The method was valid in the presence of hydrolytic degradants up to $20 \%$. By this method the bimatoprost could be analysis without any interference from its degradants (Table 4).

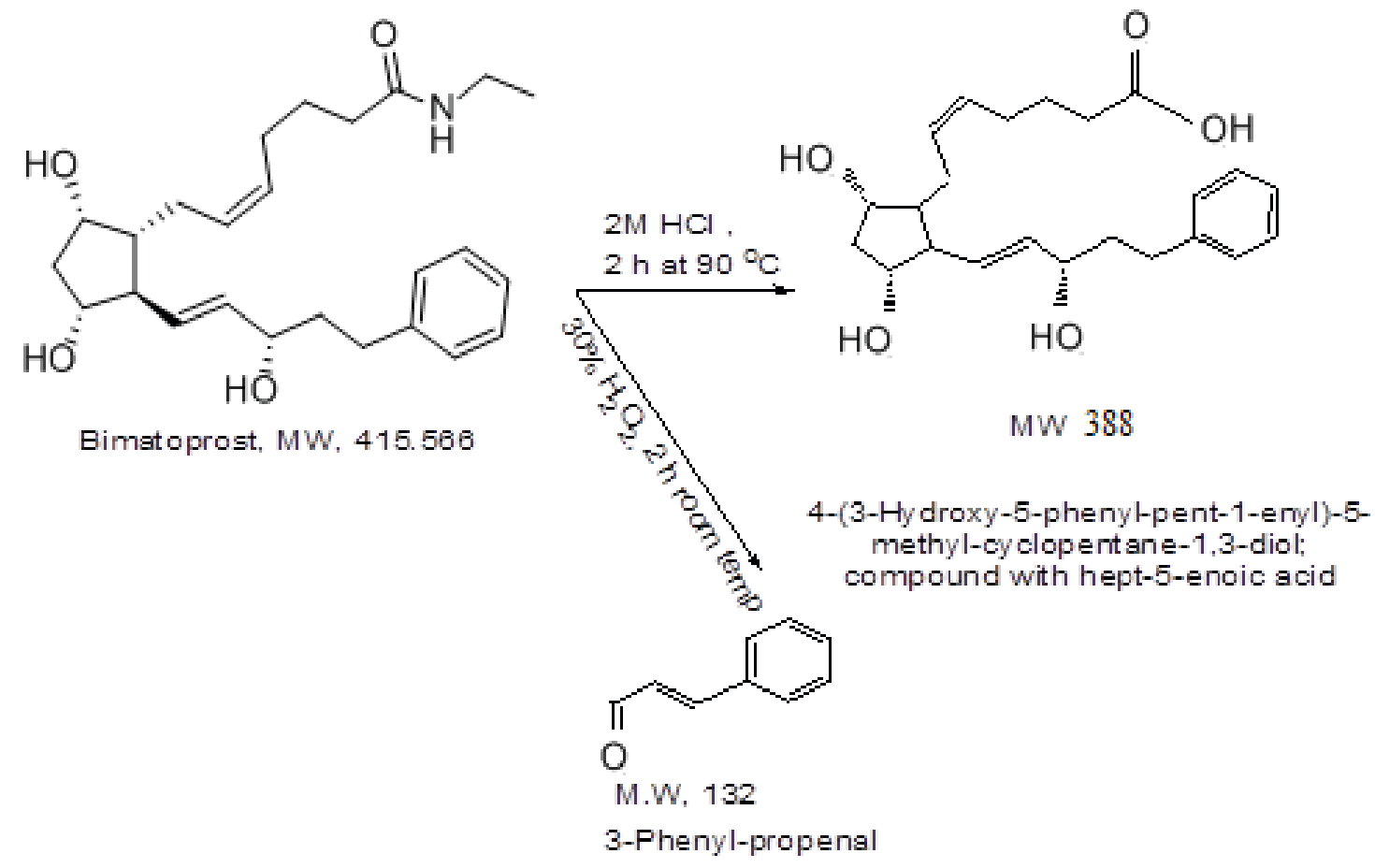

Scheme 1: Suggested scheme of degradation products of bimatoprost. 
Citation: Mohammed W, Safaa T, Abou El-Alamin MM, Nahla NS, Elabd MA (2018) Utility of Synchronous Spectrofluorimetric Method for Rapid Selective Determination of Bimatoprost: Stress Stability Study and Green Analytical Application. Pharm Anal Acta 9: 600. doi: 10.4172/21532435.1000600

Page 5 of 6

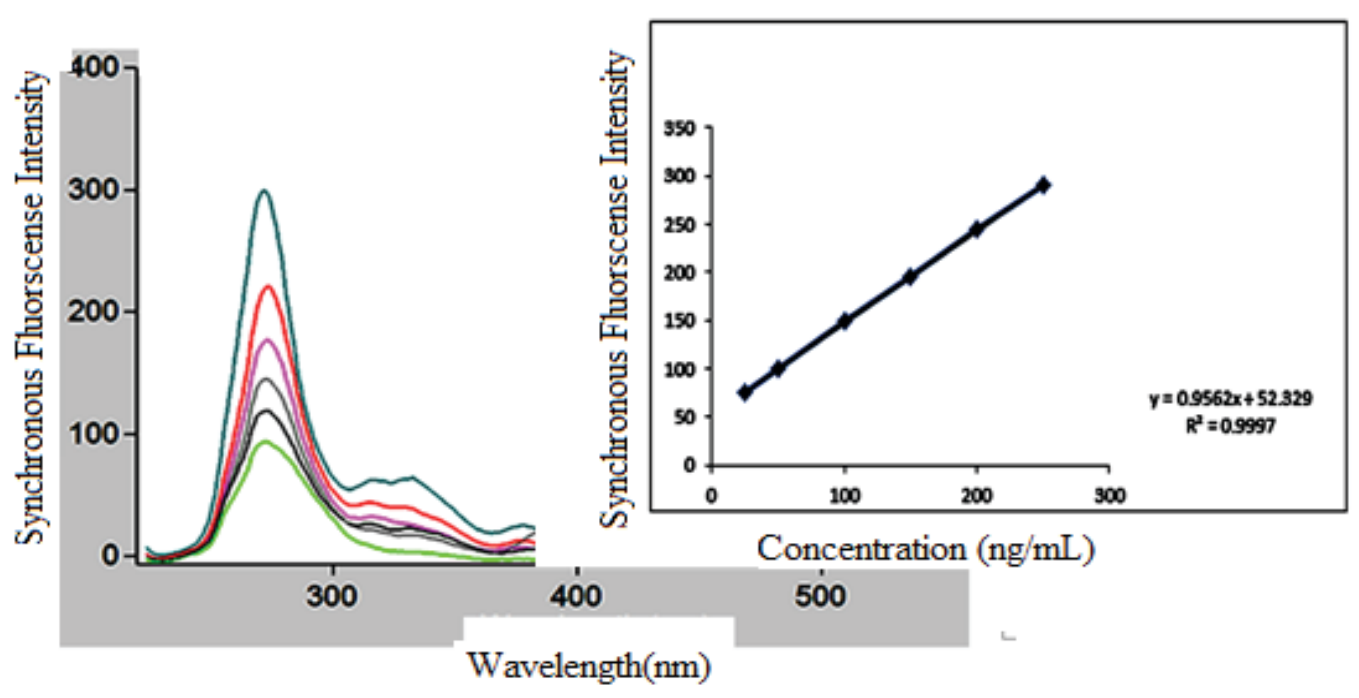

Figure 4: Synchronous fluorescence spectra of bimatoprost $(25-250 \mathrm{ng} / \mathrm{mL}) \lambda 270 \mathrm{~nm}$ using $\Delta \lambda=30$.

\begin{tabular}{|c|c|}
\hline Parameters & $\begin{array}{l}\text { Synchronous spectrofluorimetric } \\
\text { method }\end{array}$ \\
\hline Linearity range & $25-250 \mathrm{ng} / \mathrm{mL}$ \\
\hline LOD & $0.05 \mathrm{ng} / \mathrm{mL}$ \\
\hline LOQ & $0.18 \mathrm{ng} / \mathrm{mL}$ \\
\hline \multicolumn{2}{|c|}{ Accuracy ${ }^{*}$} \\
\hline Mean \pm RSD $\%$ & $99.39 \pm 1.08$ \\
\hline \multicolumn{2}{|c|}{ Regression } \\
\hline Slope & 0.96 \\
\hline SE of slope & 0.008 \\
\hline Confidence limit of slope ${ }^{* *}$ & $0.93-0.97$ \\
\hline Intercept & 52.32 \\
\hline SE of intercept & 1.24 \\
\hline Confidence limit of intercept ${ }^{*}$ & $48.86-55.79$ \\
\hline Correlation coefficient & 0.9996 \\
\hline SE of estimation & 1.6 \\
\hline \multicolumn{2}{|c|}{$n=5, " 95 \%$ Confidence limit } \\
\hline
\end{tabular}

Table 1: Validation parameters obtained by applying the developed synchronous spectrofluorimetric method

\begin{tabular}{|c|c|c|}
\hline Values & $\begin{array}{c}\text { Proposed synchronous } \\
\text { spectrofluorimetric } \\
\text { method }\end{array}$ & Manufacture* method \\
\hline Mean & 99.39 & 100.29 \\
\hline Standard deviation (SD) & 1.08 & 1.17 \\
\hline Variance $\left(\mathrm{S}^{2}\right)$ & 1.16 & 1.36 \\
\hline $\mathrm{N}$ & 5 & 5 \\
\hline$F(5.05)^{* *}$ & 2.43 & \\
\hline$t(1.812)^{* *}$ & 1.49 & \\
\hline
\end{tabular}

Table 2: Statistical comparison between the proposed synchronous spectrofluorimetric method and manufacture method for determination of bimatoprost in drug substance.

\begin{tabular}{|c|c|c|c|}
\hline \multirow{2}{*}{ Drug substance } & $\begin{array}{c}\text { Concentration } \\
\text { added } \\
\text { ng/mL }\end{array}$ & \multicolumn{2}{|c|}{ Precision* RSD\% } \\
\cline { 2 - 4 } & 50 & Intra & Inter \\
\hline \multirow{2}{*}{ Bimatoprost } & 100 & 0.02 & 0.005 \\
& 150 & 0.01 & 0.01 \\
\hline \multicolumn{2}{|c}{$* \mathrm{n}=3$} \\
\hline
\end{tabular}

Table 3: Intra and inter-day precision of the developed synchronous spectrofluorimetric method for analysis of bimatoprost in drug substance.

\begin{tabular}{|c|c|c|}
\hline \multicolumn{2}{|c|}{ Ratios of bimatoprost and its degradants } & $\begin{array}{c}\text { Recovery* \% of intact } \\
\text { drug }\end{array}$ \\
\hline $\begin{array}{c}\text { Intact } \\
\text { ng }\end{array}$ & $\begin{array}{c}\text { Acid degradant } \\
\text { ng }\end{array}$ & 101.81 \\
160 & 40 & 98.10 \\
180 & 20 & 98.05 \\
190 & 10 & \\
& Mean \pm RSD\% & $99.31 \pm 0.02$ \\
\hline \multicolumn{2}{|c|}{} \\
\hline \multicolumn{2}{|c|}{} \\
\hline
\end{tabular}

Table 4: Specificity of the developed synchronous spectrofluorimetric method for the determination of bimatoprost in laboratory prepared mixtures with its degradants.

\begin{tabular}{|c|c|c|}
\hline $\begin{array}{c}\text { Lumigen } \\
(\mathbf{0 . 0 3} \% \text { of } \\
\text { Bimatoprost) }\end{array}$ & $\begin{array}{c}\text { Proposed method } \\
\text { Recovery\%* of claimed } \\
\text { amount\% } \% \text { RSD }\end{array}$ & $\begin{array}{c}\text { Manufacture *method } \\
\text { Recovery\%* of claimed } \\
\text { amount } \pm \text { RSD }\end{array}$ \\
\hline & $92.96 \pm 1.003$ & $95.58 \pm 0.98$ \\
\hline
\end{tabular}

Table 5: Application of the developed developed synchronous spectrofluorimetric method for determination of bimatoprost in drug product.

\begin{tabular}{|c|c|c|c|}
\hline Preparation & $\begin{array}{c}\text { Amount taken } \\
\mathrm{ng} / \mathrm{mL}\end{array}$ & $\begin{array}{c}\text { Pure added } \\
\mathrm{ng} / \mathrm{mL}\end{array}$ & $\begin{array}{c}\text { Found recovery } \% \pm \\
\mathrm{RSD} \\
\mathrm{ng} / \mathrm{mL}\end{array}$ \\
\hline $\begin{array}{c}\text { Lumigen }^{\circledR} \\
(0.03 \% \\
\text { bimatoprost) }\end{array}$ & 150 & $\begin{array}{c}25 \\
50 \\
100\end{array}$ & $\begin{array}{c}98.6 \pm 0.087 \\
100.92 \pm 1.231 \\
98.67 \pm 0.914\end{array}$ \\
\hline
\end{tabular}

Table 6: Results of application of standard addition technique for determination of Bimatoprost by the developed synchronous spectrofluorimetric method.

\section{Application of the developed method}

The developed method was used for estimation of bimatoprost in its ophthalmic preparation and compared with the method supplied by the manufacturer (Table 5). The standard addition technique was applied for further assessing the accuracy as shown in Table 6.

\section{Conclusion}

The synchronous spectrofluorometric method is a new simple, sensitive method, that was explored for the simultaneous determination of bimatoprost and hydrolytic degradant in binary mixture. That 
Citation: Mohammed W, Safaa T, Abou El-Alamin MM, Nahla NS, Elabd MA (2018) Utility of Synchronous Spectrofluorimetric Method for Rapid Selective Determination of Bimatoprost: Stress Stability Study and Green Analytical Application. Pharm Anal Acta 9: 600. doi: 10.4172/21532435.1000600

Page 6 of 6

method could be applied to the estimating of bimatoprost in its raw material and drug product. The routine quality control testing and drug stability monitoring can using that developed method readily.

The synchronous spectrofluorometric method is considered green developed method, as all measurements applied in water with high effectiveness, and provides low hazards, no harmful effects on environment, so it is consider eco-friendly with environment.

\section{Author's Contributions}

There is great contributions from all Authors to introduce that paper, where all the work under their supervision and continuous reviewing.

\section{Acknowledgements} work.

First, great thanks for GOD who offers to me all responsibilities to get that

Great thanks for all my professors who they are contributing with me in that paper.

Great thanks for my faculty and NODCAR, and my lovely home EYGPT.

\section{References}

1. Sean CS, Paul B (2009) Martindale: the complete drug reference.

2. Chen M, Cheng C, Chen Y, Chou C, Hsu W (2006) Effects of bimatoprost $0.03 \%$ on ocular hemodynamics in normal tension glaucoma. J Ocul Pharmacol Ther 22: 188-193.

3. https://dvmbooks.weebly.com/uploads/2/2/3/6/22365786/2._goodman_and_ gilman.pdf

4. Kruse P, Rieck P, Sherif Z, Liekfeld A (2006) Cystoid macular edema in a pseudophakic patient after several glaucoma procedures. Is local therapy with bimatoprost the reason?. Klinische Monatsblätter für Augenheilkunde 223:
534-537.

5. Steinhäuser S (2006) Decreased high-density lipoprotein serum levels associated with topical bimatoprost therapy. Optometry 77: 177-179.

6. Park J, Cho HK, Moon JI (2011) Changes to upper eyelid orbital fat from use of topical bimatoprost, travoprost, and latanoprost. Jpn J Ophthalmol Soc 55: 22-27.

7. Jayaprakasam A, Ghazi-Nouri S (2010) Periorbital fat atrophy-an unfamiliar side effect of prostaglandin analogues. Orbit 29: 357-359.

8. Filippopoulos T, Paula JS, Torun N, Hatton MP, Pasquale LR, et al. (2008) Periorbital changes associated with topical bimatoprost. Ophthalmol Plast Reconstr Surg 24: 302-307.

9. Krishna PM, Rao BT, Raju MB, Rao CN, Kumar RK, et al. (2011) Determination of a novel impurity by LC-MASS and chromatographic separation of bimatoprost, isomers and their impurities by UPLC. J Pharm Res 4: 2381-2383.

10. Kumar SS, Natraj K, Khan A, Kumar BK, Rao JV (2011) Development and validation of RP-HPLC method for estimation of bimatoprost in pharmaceutical dosage forms. J Pharm Res 4: 3733-3734.

11. Marchei E, Orsi DD, Guarino C, Rotolo MC, Graziano S, et al. (2016) High performance liquid chromatography tandem mass spectrometry measurement of bimatoprost, latanoprost and travoprost in eyelash enhancing cosmetic serums. Cosmetics 3: 4

12. Chen GZ, Huang XZ, Xu JG, Zheng ZZ, Wang ZB (1990) The methods of fluorescence analysis. Science Press 112.

13. Patra D, Mishra AK (2002) Recent development in multicomponent synchronous fluorescence scan analysis. Trends Anal Chem 21: 787-798.

14. https://www.chemi-pharm.com/en/about-us\#quality

15. https://www.fda.gov/downloads/drugs/guidances/ucm073384.pdf

16. https://tsoshop.co.uk/Medicine/Pharmacopoeia/United-StatesPharmacopeia/?DI=644572 